\title{
COMPARATIVE ANALYSIS OF EFFICACY AND SAFETY OF DIACEREIN VERSUS S-ADENOSYL METHIONINE IN THE MANAGEMENT OF OSTEOARTHRITIS OF KNEE JOINT
}

\author{
GAYATHRI C. R. ${ }^{1}$, VANITHA SAMUEL ${ }^{2}$, JOHN WILLIAM FELIX ${ }^{3}$, NIRMALA P. ${ }^{4}$ \\ Department of Pharmacology, Rajah Muthiah Medical College, Annamalai University, Chidambaram, Tamil Nadu, India \\ Email: gay3.gayu23@gmail.com
}

Received: 20 Aug 2017, Revised and Accepted: 13 Oct 2017

\begin{abstract}
Objective: Osteoarthritis $(\mathrm{OA})$ the most common type of arthritis is a degenerative joint disease primarily affecting the articular cartilage and its surrounding tissue. Drugs like Diacerein and S-adenosyl methionine (SAMe) are used to remodel the cartilage and slow the progression of the disease, by acting through different mechanisms. Though there is documented evidence of the efficacy of both agents used individually in several clinical trials only a few studies report a comparison. To analyse the efficacy and safety of Diacerein Versus S-adenosyl methionine in the treatment
\end{abstract} of Osteoarthritis of the knee joint.

Methods: A prospective randomised interventional study was planned comparing diacerein with SAMe for $12 \mathrm{w}$ in the management of OA of the knee. 40 patients in each group were randomly assigned to receive either diacerein $50 \mathrm{mg}$ twice daily or S-adenosyl methionine $200 \mathrm{mg}$ thrice daily for $12 \mathrm{w}$. Both groups received a short course of diclofenac $50 \mathrm{mg}$ bd for one week, to tide over the acute symptoms.

Results: Assessment of both drugs individually showed an equieffective potential in reducing osteoarthritis pain over a period of $12 \mathrm{w}$. But the comparison between the two groups showed a marginal improvement in pain relief from the $4^{\text {th }}$ to $12^{\text {th }}$ week of assessment in the diacerein group.

Conclusion: Both the drugs for the treatment of $\mathrm{OA}$, were shown to be effective in relieving pain but with a slower onset of action. Since no radiological changes were observed during the 12-week protocol, studies of longer duration are needed to evaluate the long-term effectiveness of these drugs.

Keywords: Osteoarthritis, Diacerein, S-adenosyl methionine, Diclofenac

(c) 2017 The Authors. Published by Innovare Academic Sciences Pvt Ltd. This is an open access article under the CC BY license (http://creativecommons.org/licenses/by/4.0/) DOI: http://dx.doi.org/10.22159/ijcpr.2017v9i6.23428

\section{INTRODUCTION}

Joint diseases form one of the most important groups of crippling diseases in the world. Arthritis, a disease of epidemic proportion is extremely debilitating and has been in existence for many centuries, is frequently encountered in the geriatric age group [1]. Arthritis impairs physical activity, cripples affected joints and restricts movements to a large extent. These days, arthritis per se is the only cause of prolonged disability in the world. Though it does not kill, it keeps the sufferer deprived of his work, and both young and old, male and female, have been mercilessly attacked by this disease [2]. Osteoarthritis (OA) the most common type of arthritis, is also known as degenerative arthritis or "wear" and "tear" arthritis or Osteoarthrosis. It is a degenerative joint disease primarily affecting the articular cartilage and its surrounding tissue [3]. Inflammation, however, is secondary to the disease and not the cause. In India, the prevalence of Osteoarthritis is around 24.9\% [4] accounting for the frequent cause of pain, loss of function and disability in adults. It occurs $2^{\text {nd }}$ to Ischemic heart disease with more than $30 \%$ of females exhibiting the disease by the age of 65 y [5]. World Health Organization estimates that $\mathrm{OA}$ is a cause of disability in at least $10 \%$ of the population over age $60 \mathrm{y}$ and OA affects the lives of more than 20 million Americans. The knee joint being the largest synovial joint of the body, is frequently involved in a chronic joint disease like OA. It is broadly grouped into primary (Idiopathic) or secondary to metabolic conditions, anatomic abnormalities, trauma or inflammatory arthritis. The major factor involved is 'uneven distribution of load stresses across the articulating surface in a joint. Although $\mathrm{OA}$ was previously thought to be a progressive, degenerative disorder, recent evidence has resulted in ambiguity concerning the pathogenesis and natural history of OA. It is now known that spontaneous arrest or reversal of the disease can occur [6]. The main objectives in the management of $\mathrm{OA}$ are to reduce symptoms, minimise functional disability, limit the progression of structural changes and ultimately delay the need for surgery. Conventional pharmacological treatment consists primarily of analgesics, NSAIDS and newer cyclooxygenase (COX-2) specific inhibitors focused mainly on alleviating the pain associated with this condition. Use of analgesics/NSAID increases the risk of upper gastrointestinal adverse effects and does not affect the underlying pathogenesis of particular diseases. Several disease-modifying agents which help to preserve the existing cartilage and slow degeneration are in vogue. But these agents pose several adverse effects which hamper patient compliance. Hence, there is a continuous search for new and better drugs for OA [7]. Drugs like Diacerein and S-adenosyl methionine are used to remodel the cartilage and slow the progression of the disease. Diacerein is an interleukin-1beta inhibitor and is classified as a symptomatic slowacting drug in OA. (SYSADOA). S-adenosyl methionine is a dietary supplement also used in the management of OA. It is known to reduce pain by increasing the synthesis of proteoglycans by human articular chondrocytes. Such drugs have a slow onset of efficacy and a longer carry-over effect once treatment is interrupted [8]. There is documented evidence of the efficacy of both these agents being used individually in several clinical trials. Only a few studies report a comparison of their efficacy. Hence a comparison of agents like Diacerein Versus S-adenosyl methionine along with short course NSAIDS will help us to evaluate the course of disease progression as well as its effectiveness in the early or late stage of Osteoarthritis of knee joint [9].

\section{MATERIALS AND METHODS}

The present study was a prospective, randomized interventional study of subjects with knee OA for a period of $12 \mathrm{w}$. This duration was chosen based on results observed in several studies, which highlighted a delay of action by both drugs on the signs and symptoms of $\mathrm{OA}$ and also to evaluate the drug safety profile. Approval was obtained from Institutional Ethics Committee before initiating the study. The study was carried out in the Orthopaedic outpatient department of Rajah Muthiah Medical College and Hospital, Chidambaram from March 2016 to April 2017. A total of 80 
patients were enrolled in the study with a diagnosis of either primary or secondary OA, either unilaterally or involving both the knees. The age group of patients was between 40-70 y. Patients were randomised to receive either diacerein or S-adenosyl methionine daily for $12 \mathrm{w}$ along with short course NSAID to assess the carryover effect of both the drugs. The patient returned for assessment after the baseline visit at weeks 1, 4 and 12. Telephone calls at weeks 6 and 8 were made to ensure compliance during the follow-up period. The NSAID diclofenac $50 \mathrm{mg}$ twice a day was administered orally for a short course of one week. Patients were also allowed to take it when required as a rescue analgesic during the whole study period in case of severe pain. Patients were asked to record the number of diclofenac tablets used per day in a patient diary. No other systemic or intra articular drugs for $\mathrm{OA}$ were allowed during the study.

\section{Inclusion criteria}

The presences of symptomatic disease with pain present most days or crepitus on the motion. Two-view radiographs of the affected knee was obtained showing radiographic evidence of $\mathrm{OA}$ knee with a reduction in joint space and presence of osteophytes.

\section{Exclusion criteria}

Clinical evidence of infection, polyarthralgia, rheumatoid arthritis, uncontrolled hypertension, Congestive heart failure, patients on drugs for psychiatric illness. Patients were not retained for the study if they had a serious concomitant medical illness or knee surgery planned within the following 6 mo.

\section{Drugs}

S-adenosyl methionine used in this study was enteric coated $200 \mathrm{mg}$ tablets, each containing S-Adenosyl L-methionine p-toluenesulfonate equivalent to S-Adenosyl L-methionine ion $200 \mathrm{mg}$ marketed by Sun pharma laboratories Ltd. Diacerein capsules equivalent to diacerein IP $50 \mathrm{mg}$ manufactured by Glenmark Pharmaceuticals was purchased from the local pharmacy. Tablet diclofenac $50 \mathrm{mg}$ from the hospital pharmacy was prescribed to the patients.

\section{Evaluation of efficacy and safety}

The primary efficacy parameter was the patient's assessment of pain on movement using Lysholm knee scoring scale with a total score of 100 grading of $<65$-poor, 65-83-fair, 84-90-good and $>90$-Excellent. An improvement in score indicates the reduction in pain level. Patients were assessed during each clinical visit at week 0 , week 1 , week 4 and at $12^{\text {th }}$ week. The data was recorded in a data sheet containing patient's basic details. Clinical symptoms like pain, duration of the disease, morning stiffness and restricted movements with the final diagnosis was recorded. Radiographs were taken at baseline and at the end of the $12^{\text {th }}$ week to evaluate any improvement in radiological changes. All adverse effects reported by the patients during the study period were recorded on the Case report form and classified in terms of type, time of onset, severity, duration, and outcome. Subjects were made aware of possible side effects during the first visit. Adverse reactions were monitored with health diaries, clinical interviews at visits 1,4 and $12 \mathrm{w}$.

\section{Statistical analysis}

The statistical analysis was carried out with SYSTA 12 version software. To compare the demographic characterises of the patients either ' $\mathrm{t}$ ' test (quantitative variable) or chi-square test (qualitative variable) has been applied. To compare the two drugs efficacy, $2 \times 4$ ANOVA repeated test has been applied. If the results are significant corresponding "Repeated contrast test" has been applied. Level of significance was set at $(\mathrm{P}<0.05)$.

\section{RESULTS}

A total of 80 subjects met the inclusion criteria and were enrolled in this study. After completing the initial assessment, 40 subjects in each group were randomly assigned to receive either diacerein $50 \mathrm{mg} /$ day twice daily or S-adenosyl methionine $200 \mathrm{mg} /$ day thrice daily.

Table 1: Demographics and baseline characteristics

\begin{tabular}{|c|c|c|c|c|c|c|}
\hline \multicolumn{2}{|l|}{ Characteristic } & \multicolumn{2}{|c|}{ Diacerein } & \multicolumn{2}{|c|}{ S-adenosyl methionine } & \multirow{2}{*}{$\begin{array}{l}\text { P value } \\
0.648\end{array}$} \\
\hline Gender & Male & 17 & $(42.5 \%)$ & 15 & $(37.5 \%)$ & \\
\hline & Female & 23 & $(57.5 \%)$ & 25 & $(62.5 \%)$ & \\
\hline \multirow[t]{2}{*}{ Age in year $( \pm S D)$} & Mean & 57.47 & $( \pm 6.46)$ & 56.17 & $( \pm 7.41)$ & 0.406 \\
\hline & Min.-Max. & $47-70$ & - & $45-70$ & - & \\
\hline \multirow[t]{2}{*}{ BMI } & Mean & 25.08 & $( \pm 2.77)$ & 25.96 & $( \pm 2.79)$ & 1. 60 \\
\hline & Min.-Max. & $20-30$ & - & $20-30.2$ & - & \\
\hline \multirow[t]{3}{*}{ Affected Knee Joint } & $\mathrm{B} / \mathrm{l}$ & 13 & $(32.5 \%)$ & 15 & $(37.5 \%)$ & 0.753 \\
\hline & L Knee & 14 & $(35.0 \%)$ & 15 & $(37.5 \%)$ & \\
\hline & R Knee & 13 & $(32.5 \%)$ & 10 & $(25 \%)$ & \\
\hline \multirow[t]{4}{*}{ Duration of $\mathrm{OA}$} & $<4 \mathrm{Mo}$ & 5 & $(12.5 \%)$ & 8 & $(20.0 \%)$ & 0.590 \\
\hline & 5-8 Mo & 24 & $(60.0 \%)$ & 24 & $(60.0 \%)$ & \\
\hline & 9-12 Mo & 10 & $(25.0 \%)$ & 8 & $(20.0 \%)$ & \\
\hline & $>1 \mathrm{y}$ & 1 & $(2.5 \%)$ & 0 & $(0.0 \%)$ & \\
\hline \multicolumn{2}{|c|}{ Patients with previous NSAID intake } & 8 & $(20.0 \%)$ & 5 & $(12.5 \%)$ & 0.363 \\
\hline
\end{tabular}

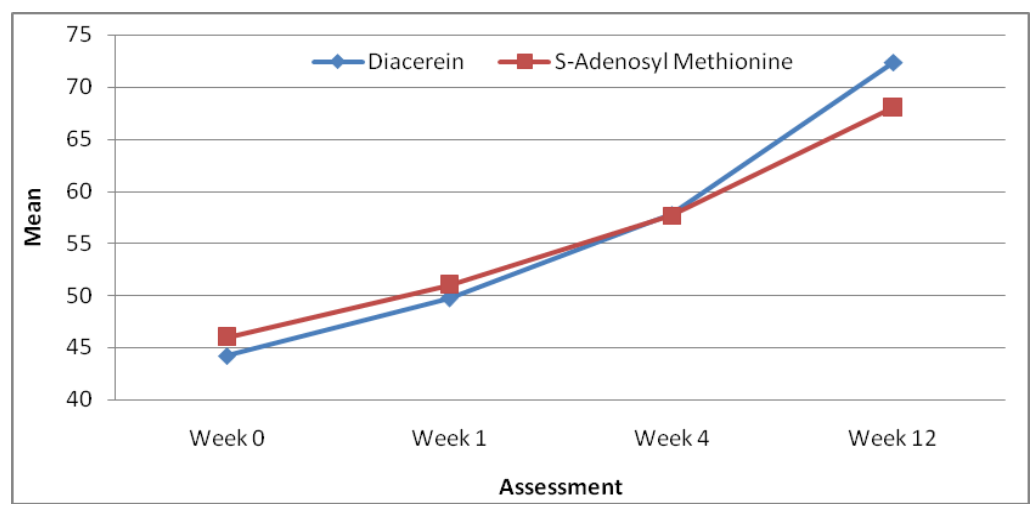

Fig. 1: Comparison of mean pain score in both treatment groups 


\section{Legend: 1}

The main baseline characteristics of the 80 subjects are summarized in table 1 . There were no significant demographic differences between subjects assigned to diacerein group and those assigned to $S$-adenosyl methionine (SAM) group. ( $p>0$. 05). The patients were predominantly female $(60 \%)$ with a mean age of 56 y $[+/-6.5$, range
45-70 y]. Subjects in the study tended not to be very obese, as indicated by an average body mass index of $25.5(+/-2$. 79). OA involving the Left knee or both knees was more frequently observed in the study population. The subjects diagnosed with OA had an average disease duration of 8-12 mo. Patients with previous NSAIDs intake (table no 1 ) were 13 patients ( 8 in the diacerein group and 5 in the SAM) who previously took diclofenac for pain relief.

Table 2: Comparison of diacerein versus SAMe using $2 \times 4$ ANOVA repeated contrast test

\begin{tabular}{|c|c|c|c|c|c|c|c|c|c|c|c|}
\hline \multirow[t]{3}{*}{ Assessment } & \multicolumn{4}{|l|}{ Group } & \multirow{2}{*}{\multicolumn{3}{|c|}{$2 \times 4$ ANOVA repeated test results }} & & \multirow{2}{*}{\multicolumn{3}{|c|}{ Repeated contrast test }} \\
\hline & \multicolumn{2}{|c|}{ Diacerein } & \multicolumn{2}{|c|}{$\begin{array}{l}\text { S-Adenosyl } \\
\text { methionine }\end{array}$} & & & & & & & \\
\hline & Mean & SD & Mean & SD & Source & $\begin{array}{l}\text { F } \\
\text { value }\end{array}$ & $\begin{array}{l}\mathbf{P} \\
\text { valve } \\
\end{array}$ & & Comparison & $\begin{array}{l}\text { F } \\
\text { value } \\
\end{array}$ & $\begin{array}{l}P \\
\text { value } \\
\end{array}$ \\
\hline Week 0 & 44.2 & $\begin{array}{l}8 . \\
2\end{array}$ & 46.000 & 6.6178 & $\begin{array}{l}\text { Between } \\
\text { subject Drugs }\end{array}$ & 0.074 & 0.786 & $\begin{array}{l}\text { Assessment } \\
* \\
\text { group }\end{array}$ & $\begin{array}{l}\text { Week } 0 \\
\text { vs } \\
\text { week } 1\end{array}$ & $\begin{array}{l}0 . \\
296\end{array}$ & 0.588 \\
\hline Week 1 & $\begin{array}{l}49 . \\
75\end{array}$ & $\begin{array}{l}7 . \\
7\end{array}$ & 51.000 & 5.9226 & $\begin{array}{l}\text { Within subject } \\
\text { Assessment }\end{array}$ & $\begin{array}{l}344 . \\
165\end{array}$ & 0.000 & & $\begin{array}{l}\text { Week } 1 \\
\text { vs week } 4\end{array}$ & $\begin{array}{l}1 . \\
338\end{array}$ & 0.251 \\
\hline Week 4 & 57.8 & $\begin{array}{l}7 . \\
6\end{array}$ & 57.650 & 6.2205 & Ass*group & 5.628 & 0.001 & & $\begin{array}{l}\text { Week } 4 \\
\text { vs week } 12\end{array}$ & $\begin{array}{l}6 . \\
992\end{array}$ & 0.010 \\
\hline Week 12 & 72.4 & $\begin{array}{l}11 . \\
3\end{array}$ & 68.025 & 6.8706 & & & & & & & \\
\hline
\end{tabular}

\section{Legend: 2}

The mean values and the statistics for the efficacy parameters are presented in table 2. The pain was assessed using Lysholm knee scoring scale. An increase in the Lysholm knee score indicates the reduction in pain level experienced by the patients. Subjects were assessed for pain at baseline, $1^{\text {st }}$ week, a $4^{\text {th }}$-week and $12^{\text {th }}$ week. The mean pain score was found to increase to a similar extent in both the groups during the $12 \mathrm{w}$ treatment period: from a mean value of 44 . $2+/-6.6$ at baseline to $724+/-6.8$ at week 12 in the diacerein group and from $46+/-6.6$ at baseline to $68.02+/-6.8$ at week 12 in SAM group. The above mean values were compared and the significant $p-$ value reveals that the pain level differs week wise. A reduction in the pain level in both groups was observed to be maximal at the end of the $12^{\text {th }}$ week. To analyze which of the two drugs is more effective, $2 \times 4$ ANOVA repeated test was applied (table no 2). The nonsignificant p-value of "between subjects-drugs" indicates in general that both the drugs are equally effective in reducing the pain level. To get more details of the efficacy of the two drugs "Within-subject" comparison has been done and the significant p-value of assessment * group indicated that there is some minute difference existing between the two drugs. Hence, the corresponding repeated contrast test was applied. The significant $p$-value between the $4^{\text {th }}$-week assessment and $12^{\text {th }}$-week assessment indicates that in SAMetreated patients, improvement in the pain score is slightly lesser than the improvement occurring in the diacerein group.

Table 3: Percentage of drug-related adverse effects with diacerein and SAMe

\begin{tabular}{|c|c|c|c|c|}
\hline \multirow[t]{2}{*}{ Adverse effects } & \multicolumn{2}{|c|}{ Diacerein } & \multicolumn{2}{|c|}{ S-adenosyl methionine } \\
\hline & No. & $\%$ & No. & $\%$ \\
\hline Present & 16 & 40.0 & 11 & 27.5 \\
\hline Absent & 24 & 60.0 & 29 & 72.5 \\
\hline
\end{tabular}

$\chi 2=2.40$ p. value $0.121(\mathrm{NS})$

Legend: 3

A significant no of patients (40\%) presented with GI-related effects in the diacerein group. Mild to moderate diarrhoea which was troublesome occurred in the diacerein group with some patients reporting abdominal pain and dyspepsia. The GIassociated adverse effects were comparatively lesser in the SAMe group (27. 5\%).

\section{Radiological pictures of severe osteoarthritis}

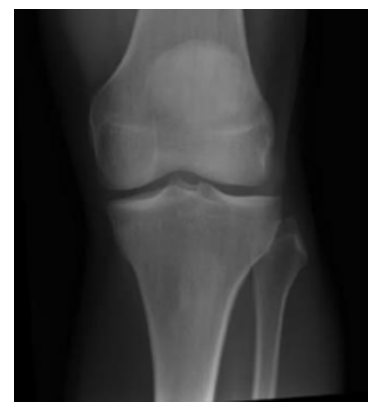

Normal x-ray knee joint

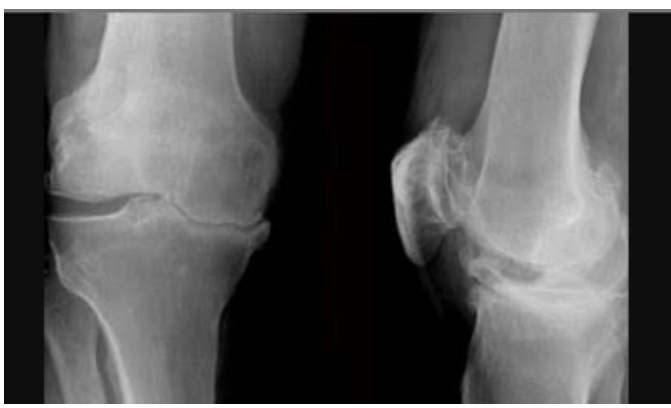

Severe osteoarthritis knee joint

X-Ray 1: Shows the comparative pictures between normal and severe osteoarthritis 


\section{Legend: 4}

$\mathrm{X}$-ray 1 shows the normal knee joint and anteroposterior (AP) view plus a lateral view of the $\mathrm{OA}$ affected knee joint. The radiographic hallmarks

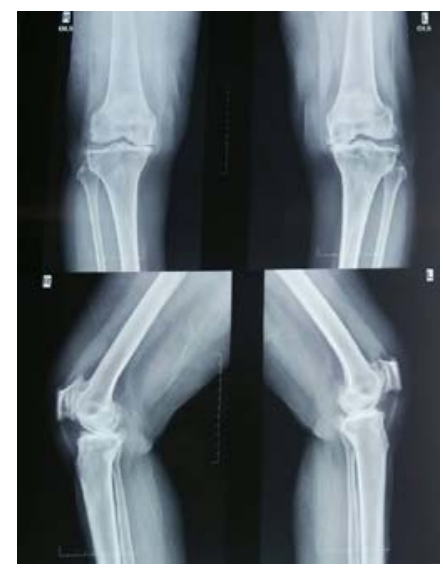

Diacerein-Before treatment of primary osteoarthritis include nonuniform joint space loss, osteophyte formation, cyst formation and subchondral sclerosis. At first, only minimal, nonuniform joint space narrowing may be present. The involved joint spaces have an asymmetric distribution.

$\mathrm{X}$-Ray 2: The anteroposterior and lateral view of the knee joint before and after diacerein treatment

\section{Legend: 5}

X-ray 2 shows knee joint of osteoarthritis patients before and after treatment with diacerein. Pre-treatment X-ray shows medial

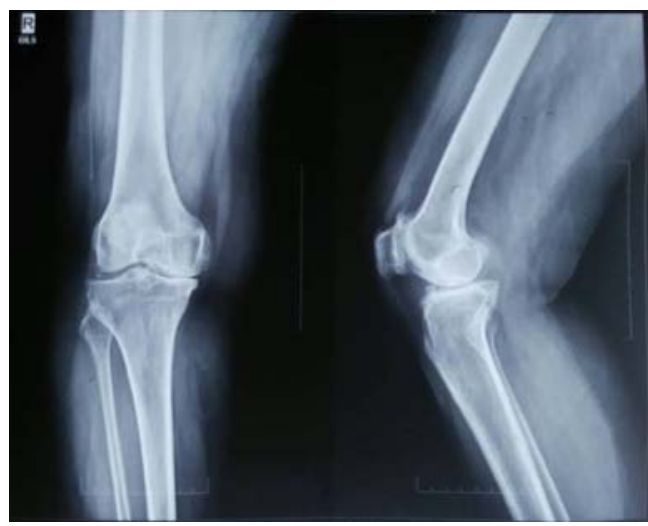

S-adenosyl methionine-Before treatment

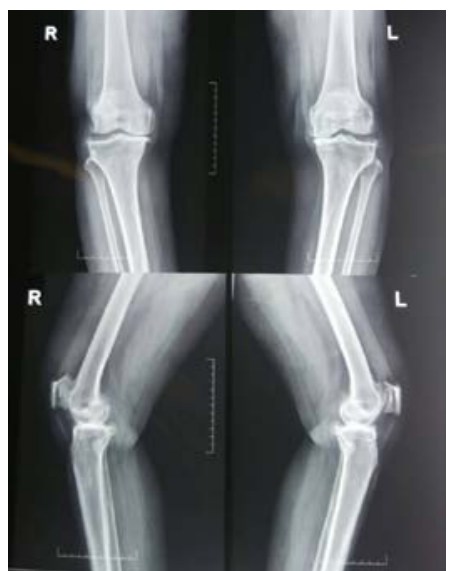

Diacerein-After treatment intercondylar joint space and femeropatellar joint space narrowing with subchondral sclerosis Osteoarthritic changes. Post-treatment with diacerein shows no significant improvement radiologically.

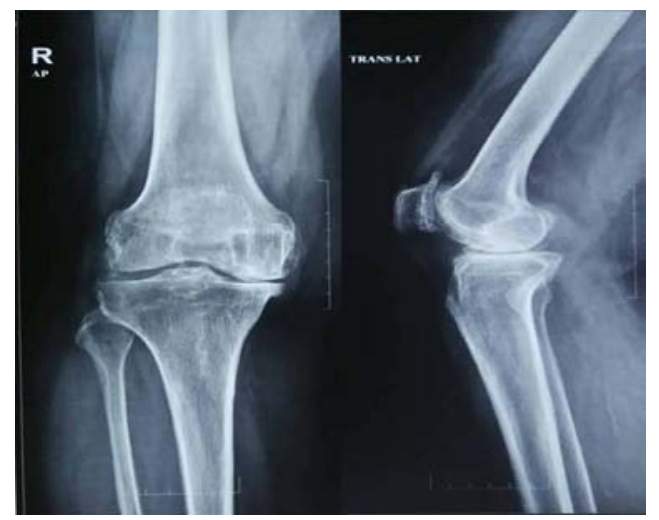

S-adenosyl methionine-After treatment

$\mathrm{X}$-Ray 3: The anteroposteiror and lateral view of the knee joint before and after treatment with S-adenosyl methionine

\section{Legend: 6}

X-ray 3 shows the knee joint surface before and after treatment of Sadenosyl methionine. Pre-treatment X-ray shows mild narrowing of medial intercondylar joint space with subchondral sclerosis and minimal osteophytes. Femoropatellar joint joint space appears narrowed with retropatellar osteophytes. Post-treatment X-ray shows no significant radiological changes observed in the affected knee joint even after $12 \mathrm{w}$ of treatment with S-adenosyl methionine.

\section{DISCUSSION}

The medical management of Osteoarthritis (OA), includes drug and non-drug therapies of which NSAIDS have been largely recommended for the control of symptoms of pain and inflammation. Based on an increase in our understanding of pathogenetic mechanisms underlying the damage to the affected joint, pharmacological agents have been developed [10]. Their mechanism of action is aimed at inhibition of matrix-degrading enzymes, such as collagenase, gelatinase, or stromelysin as well as inhibition of cytokines, such as TNF alpha or interleukin-1 beta or signaling pathways involved in the synthesis of such cytokines. Diacerein, in vitro and in vivo, has been shown to inhibit the production and the activity of interleukin- 1 and the secretion of metalloproteases, without affecting the synthesis of prostaglandins [11]. S-adenosyl methionine (SAMe), a dietary supplement and a metabolite of the essential amino acid methionine, functions as a methyl donor in many biochemical reactions. In vitro studies have documented that S-adenosyl methionine acts by stimulating the synthesis of proteoglycans by human articular chondrocytes [12]

Some patients reported marked improvement in their OA during the clinical trials of SAMe in the treatment for depression [13]. To our knowledge, only a few clinical trials have reported the efficacy of diacerein versus $\mathrm{S}$-adenosyl methionine in the management of $\mathrm{OA}$ Hence, this study was carried out to assess the efficacy and safety of diacerein, in comparison with S-adenosyl methionine along with short course NSAIDs in patients with painful knee OA. Results for the primary efficacy parameter, pain assessment by Lysholm knee scoring scale showed that both the agents caused a reduction in pain weekly, (vide table 2) starting from the $4^{\text {th }}$ until the $12^{\text {th }}$ week of 
treatment. These findings were consistent with the results of other randomized, NSAID or placebo-controlled studies with diacerein and SAM [14-15] our results indicate that both diacerein and SAMe were equally effective individually in relieving the pain of OA. NSAID's relieve the acute symptoms but long-term administration does not modify the course of the disease and is accompanied by serious adverse effects. It is clear from our results that these drugs have a slow onset of action, requiring almost one month of treatment prior to achieving these effects. Since NSAIDS have a definite advantage during the acute phase, they were administered initially in the first week of therapy [16]. Diacerein is an IL-1b inhibitor with symptom and structure-modifying properties in OA. In vitro studies at the premembrane level reveal that diacerein and its active metabolite rhein down-regulate the activity of IL-1b by significantly decreasing the number of IL-1receptors on the cell surface, and by binding of IL-1 to its receptor significantly increasing the release of IL-1 receptor antagonist [17]. At the post-membrane level, diacerein inhibits the release of inflammatory and cartilage-degrading factors, inhibiting the activation of nuclear factor-kappa B [18]. It stimulates the production of cartilage growth factors such as transforming growth factor-beta and cartilage components, even in the presence of IL-1b [19]. This may explain the cartilage protective effects of diacerein observed in animal models of OA [20]. The analysis of beneficial effects showing a delay in onset of action was observed in both the drugs, statistically significant at $12^{\text {th }}$ week. This was also seen in a recent randomised, double-dummy, diclofenac-controlled study with diacerein [21]. Sustained relief lasting 1-2 mo seen after discontinuation of the drugs indicates a carryover effect of this treatment as evidenced in the 3-year structure-modifying ECHODIAH study [22]. Concerning safety, a similar incidence of adverse effects was observed in both the treatment groups. No incidence of upper GI effects, such as gastric or duodenal ulcers were observed in the diacerein group indicating that diacerein does not inhibit COX and hence prostaglandins [23]. Patients treated with SAMe had complaints of mild gastritis. The major AE reported with diacerein was discoloration of urine, due to the elimination of its metabolites via the kidney, which is of no clinical significance [24]. Although the incidence of diarrhoea was higher in the diacerein group, the event may be considered more as patient discomfort. Overall the adverse effects were more in diacerein group as compared to SAMe. However, it seems reasonable to use surrogates, such as radiographically assessable changes, (video image) to monitor disease progression in OA. Various scientific societies recommend the use of change in minimal JSW as a radiographic variable for the assessment of progression [25]. The 12-week study did not reveal any significant radiological change. Studies of drug intake for more than 6 mo may have a beneficial role in the radiological changes in patients with $\mathrm{OA}$ due to its long-term carryover effect. Our study results reveal an equieffective potential of both drugs individually in reducing pain in OA patients with diseasemodifying action. Comparison between the two shows a marginally greater improvement in Diacerein group versus SAMe in $4^{\text {th }}$ to the $12^{\text {th }}$ week alone as evidenced by the mean pain score values (vide table 2). The adverse effects were also more significant only in the Diacerein group (Video table 3).

\section{CONCLUSION}

Based on their clinical efficacy in relieving the signs and symptoms of $\mathrm{OA}$, its structure modifying potential, and safety profile, both diacerein, and SAMe constitute a novel approach to the treatment of OA. It can be envisioned as a treatment for the short and long-term management of this disease. We need more elaborate studies to clarify how to deal with such a heterogeneous and frequent disease. Further research is needed to discover a drug that has the ability to change the course of the disease. These drugs have a slow onset of action, with long-term carryover effect and lesser side effects when compared to long-term NSAIDS. Finally, diacerein and S-adenosyl methionine could be especially used in elderly OA patients with cardiovascular problems that preclude the use of NSAIDS.

\section{ACKNOWLEDGEMENT}

I am thankful to the Professor and HOD, Department of Pharmacology, Professors of the Department of Pharmacology,
Rajah Muthiah Medical College, Professors from the Department of Orthopaedics and co-postgraduates for their inspiration to take up this study and their guidance through each and every step of this research work, by giving useful suggestions and made me complete this work successfully.

\section{CONFLICT OF INTERESTS}

Declared none

\section{REFERENCES}

1. Lawerence RC, Helmick CG, Arnett FC, Deyo RA, Felson DT, Giannini EH, et al. Estimates of the prevalence of arthritis and selected musculoskeletal disorders in the United States. Arthritis Rheum 1998;41:778-99.

2. ACR Subcommittee on Osteoarthritis Guidelines. Recommendations for the medical management of osteoarthritis of the hip and knee. Arthritis Rheum 2000;43:1905-15.

3. Felson DT, Chassion CE, Hill CL, Totterman SMS, Gale ME, Skinner KM, et al. The association of bone marrow lesions with pain in knee osteoarthritis. Ann Int Med 2001;134:541-9.

4. Aggarwal V. Prevalence of rheumatic diseases in India. J K Sci 2003;5:48-9.

5. Arden N, Nevitt MC. Osteoarthritis epidemiology. Best Pract Clin Rheumatol 2006;20:3-25.

6. Yun Wang, Xianling Zhao. Mitochondrial biogenesis is impaired in osteoarthritis chondrocytes but reversible via peroxisome proliferator-activated receptor gamma. Arthritis Rheum 2015;67:2141-53.

7. Recommendations for the medical management of osteoarthritis of the hip and knee: 2000 update. American College of Rheumatology Subcommittee on Osteoarthritis Guidelines. Arthritis Rheum 2010;43:1905-15.

8. Bottiglieri T. S-Adenosyl-L-methionine (SAMe): from the bench to the bedside-molecular basis of a pleiotropic molecule. Am J Clin Nutr 2002;76:1151S-7S.

9. Turek S. The Knee. Orthopaedics: principles and their complication. $4^{\text {th }}$ edition. New Delhi: JaypeeBrothers; 1989. p. 1367-71.

10. Colville-Nash PR, Willoughby DA. COX-1, COX-2, and articular joint disease: a role of chondroprotective agents. Biorheology 2002;39:171-9.

11. Martel-Pelletier J, Mineau F, Jolicoeur FC, Cloutier JM, Pelletier JP. In vitro effects of diacerein and rhein on interleukin 1 and tumor necrosis factor-alpha system in human osteoarthritic synovium and chondrocytes. J Rheumatol 2001;25:753-62.

12. Harmand MF, Vilamitjana J, Maloche E. Effects of Sadenosylmethionine on human articular chondrocyte differentiation. Am J Med 1987;83:48-54.

13. Papakostas GI. S-adenosyl methionine in depression: a comprehensive review of the literature. Curr Psychiatry 2003;5:460-6.

14. Marcolongo R, Fioravanti A, Adami S, Tozzi E, Mian M, Zampieri A. Efficacy and tolerability of Diacerein in the treatment of osteoarthrosis. Curr Ther Res 1988;43:878-87.

15. Padova C. S-adenosyl methionine in the treatment of osteoarthritis. Rev Clin Studies. Am J Med 1987;83:60-5.

16. Jawad. Analgesics and osteoarthritis: Are treatment guidelines reflected in clinical practice? Am J Thera 2005;12:98-103.

17. Yaron M, Shirazi I, Yaron I. Anti-Interleukin-1 effects of diacerein and rhein in human osteoarthritic synovial tissue and cartilage cultures. Osteoarthritis Cartilage 2009b; 7:272-80.

18. Mendes AF, Caramona MM, de Carvalho AP, Lopes MC. Diacerhein and rhein prevent interleukin-1beta-induced nuclear factor-kappa B activation by inhibiting the degradation of inhibitor kappa B-alpha. Pharmacol Toxicol 2002;91:22e8.

19. Felisaz N, Boumediene K, Ghayor C, Herrouin JF, Bogdanowicz $\mathrm{P}$, Galera $\mathrm{P}$, et al. Stimulating effect of diacerein on TGF-b1 and b2 expression in articular chondrocytes cultured with and without interleukin-1. Osteoarthritis Cartilage 2004; 7:255e64.

20. Douni E, Sfikakis PP, Haralambous S, Fernandes P, Kollias G. Attenuation of inflammatory polyarthritis in TNF transgenic mice by diacerein: comparative analysis with dexamethasone, methotrexate and anti-TNF protocols. Arthritis Res Ther 2004;6:R65-72. 
21. Zheng WJ, Tang FL, Li J, Zhang FC, Li ZG, Su Y, et al. Efficacy and safety of diacerein in osteoarthritis of the knee: a randomized, multicenter, double-dummy, diclofenac-controlled trial in China. APLAR J Rheumatol 2006;9:64-9.

22. Dougados $M$, Nguyen $M$, Berdah L, Mazieres B, Vignon E, Lequesne M. Evaluation of the structure-modifying effects of diacerein in hip osteoarthritis: ECHODIAH, a three-year, placebo-controlled trial. Arthritis Rheum 2001;44:2539-47.

23. Pelletier JP, Mineau F, Fernandes JC, Duval N, Martel-Pelletier J. Diacerhein and Rhein reduce the interleukin $1 \mathrm{~b}$ stimulated inducible nitric oxide synthesis level and activity while stimulating cyclooxygenase-2 synthesis in human osteoarthritic chondrocytes. J Rheumatol 1998;25:2417-24.

24. Nicolas P, Todd M, Padoin C, Petitjean O. Clinical pharmacokinetics of diacerein. Clin Pharmacokinet 1998;35:347-59.

25. Dougados $M$, The group for the Respect of Ethics and Excellence in Sciences (GREES) Osteoarthritis Section. Recommendations for the registration of drugs used in the treatment of osteoarthritis. Ann Rheum Dis 1996;55:552-7. 